\title{
The Training of Young Teachers' Teaching Ability in Colleges and Universities by Teaching Courseware
}

\author{
Zhang Yong-ming ${ }^{1, a^{*}}$
}

${ }^{1}$ Department of Mathematics of Beijing Institute of Graphic Communication, Beijing, China

abjzym@bigc.edu.cn

${ }^{*}$ Corresponding author

\begin{abstract}
Chinese higher education has entered the stage of popular education since 1999.Along with the entering into the stage of popularization of higher education, It is the common problems that improves the quality of education in the world. The young teacher teams in colleges and universities in our country expands constantly, the teaching ability of young teacher is related directly to the quality of education. From the current situation of the young teachers' teaching ability and the factors which influence the teaching ability of young teachers, we presents the concept and implement scheme of the training of young teachers' teaching ability by teaching courseware.
\end{abstract}

Keywords: Young teacher,Teaching ability,Teaching courseware.

\author{
以教学课件为抓手培养高校青年教师的教学能力 \\ 张永明 ${ }^{1,} \mathrm{a}^{*}$ \\ ${ }^{1}$ 北京印刷学院基础部, 黄村, 大兴, 北京, 中国 \\ abjzym@bigc.edu.cn \\ *通讯作者
}

中文摘要. 我国的高等教育自1999年开始 步入大众化教育阶段, 提高教育质量是各国 高等教育进入大众化阶段后面临的共同问 题, 随着我国高等院校青年教师的队伍不断 扩大, 青年教师的教学能力直接关系到教育 质量。我们从青年教师教学能力的现状及影 响青年教师教学能力的因素出发, 提出以教 学课件为抓手培养高校青年教师教学能力 的理念和实施方案。
关键词: 青年教师; 教学能力; 教学课件

\section{1. 引言}

影响青年教师教学能力的因素及专家 认同度 ${ }^{[1]}$ 如表 1 。 
表1 影响教师教学能力的因素及专家认同度

\begin{tabular}{|c|c|}
\hline 影响因素 & 专家占比 \\
\hline 学科知识的深度 & $84.07 \%$ \\
\hline 作为教师的表达能力 & $77.04 \%$ \\
\hline 教师的课堂管理能力 & $70.00 \%$ \\
\hline 教育学、心理学的知识素养 & $52.59 \%$ \\
\hline 关于学生学习情况的知识 & $44.44 \%$ \\
\hline 个人实践经验和能力 & $4.44 \%$ \\
\hline 责任心 & $3.33 \%$ \\
\hline 敬业精神 & $3.33 \%$ \\
\hline
\end{tabular}

对照表1中的各因素，我们从其中的前 四大因素来认识青年教师的教学能力现状。

\section{1 “学科知识的深度” 达到基本要求}

“学科知识的深度” 是影响青年教师教 学能力的第一因素, 专家认同度为 $84.07 \%$ 。 新入教学岗位的青年教师基本上都取得了 博士学位, 在学科知识的深度方面已经达到 高校的教学能力基本要求, 具备成为一名合 格教师的必要条件。

\section{2 “作为教师的表达能力” 不足}

青年教师存在一个普遍性的问题, 就是 “作为教师的表达能力” 不足, 严重影响教 学质量。培养青年教师 “作为教师的表达能 力” 是一个值得认真研究的问题。

\section{3 “教师的课堂管理能力” 欠缺及对策}

青年教师由于缺乏教学经验, 不能很好 地应对课堂教学过程中出现的各种问题, 容 易造成教学过程失控, 影响教学质量。“教 师的课堂管理能力”在影响青年教师教学能 力的各因素中位于第三位, 专家认同度为 $70 \%$, 微低于 “学科知识的深度” 和 “作为 教师的表达能力”, 所以培养青年教师的教 学能力要十分重视教师的课堂管理能力的 培养, 这可发挥老教师传帮带作用[2，3]。

\section{4 “教育学、心理学的知识素养” 缺乏 及对策}

高校青年教师大多来自非教育类专业, 他们自身的学科知识较为扎实, 但缺乏教育 学和心理学的知识素养, 这需要通过岗前培 训加以弥补[2]。

\section{2. 以课件为抓手培养高校青年教师的教学 能力的实施方案}

从青年教师的教学能力现状可以看到, 影响青年教师教学能力的第一因素“学科知 识的深度” 不需要过多关注, 第三因素 “教 师的课堂管理能力” 和第四因素 “教育学、 心理学的知识素养” 虽有不足但已有相应的 对策, 惟第二因素 “作为教师的表达能力”, 我们还没有很好的对策, 所以培养青年教师 的教学能力, 关键是培养青年教师 “作为教 师的表达能力”。

结合多年的教学经验和研究, 我们意识 到 “作为教师的表达能力” 问题, 不是一般 的语言表达能力问题, 而是青年教师对教学 内容、教学方法的认识程度和运用能力的问 题, 所以要培养青年教师 “作为教师的表达 能力”, 就要在教学内容、教学方法加以辅 导, 而教学内容、教学方法的落脚点是教学 课件 (图1给出教学课件的基本构成, 其中 教学课件的形式为屏幕上显示的内容, 教学 课件的内涵不在屏幕上显示但需要教师进 行口头讲解), 为此, 我们提出以教学课件 为抓手培养高校青年教师教学能力的理念, 下面介绍以教学课件为抓手培养高校青年 教师教学能力的实施方案。

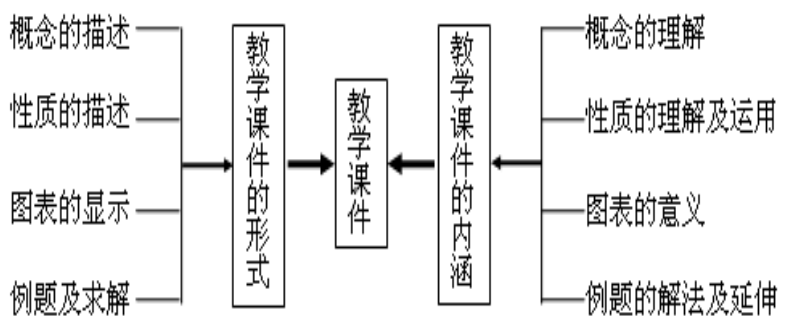

图1 教学课件的基本构成

\section{1 以老带新, 培养青年教师正确处理教 学课件的制作与课堂教学有效性的关系}

现在高校教学大都使用电子教学课件, 青年教师所用的教学课件大都不是自己制 作的, 这就出现一个问题, 就是别人在制作 教学课件时的教学设计、教学方法和教学实 施细节大都没有直接反应到教学课件的形 式上, 青年教师直接使用的效果必然很差。 比如同样一页PPT的教学内容, 课件制作人 融入了讲什么、怎么讲、为什么讲、讲完后 如何引伸等教学设计, 教学设计需要讲 10 分钟的时间, 但青年教师可能只用 $2 、 3$ 分钟 
就讲完了, 自己还觉得 “这有什么可讲的 呢? ”, 这实际上是青年教师在直接使用他 人制作的教学课件时无法保证课堂教学的 有效性的一种体现, 正如图1所示, 这是青 年教师只重视教学课件的形式而忽视教学 课件的内涵的必然结果。

为了保证课堂教学的有效性 [4], 必须 让青年教师正确处理教学课件的制作及课 堂教学有效性的关系。青年教师在独立走上 讲台之前必须经过老教师的指导, 对将要使 用的教学课件进行深入的研究, 在老教师的 质疑和引导下理解并掌握教学课件的设计 过程和教学方法, 并努力提出教学课件的修 改或完善的意见或建议, 能够正确处理教学 课件的制作与课堂教学有效性的关系, 为准 确把握、改进和使用教学课件打下良好的基 础。

\section{2 以老带新, 在实际教学过程中培养青 年教师的教学能力}

青年教师独立上课之前, 必须在老教师 的指导下经历一个完整的教学过程, 特别是 要求青年教师要认真完整地听老教师上课, 从中体会教学课件的设计理念, 老教师在使 用教学课件时的教学方法, 同时在老教师指 导下完成几次完整的训练课。

青年教师在听课之前, 让青年教师先汶 览一下教学课件, 课后总结老教师的上课情 况, 并与自己上课前的设想作对比, 与老教 师交流研讨, 以提高自身的课堂教学能力。

青年教师在训练课前后都要与老教师 进行沟通, 汲取老教师的教学经验。

上述培养过程重点是培养青年教师对 教学课件的内涵的理解、掌握和运用, 青年 教师对教学内容和教学方法的认识与体会 逐渐转变为对教学课件的内涵的正确理解 和把握。只有心中有数, 才能言出有物, “作 为教师的表达能力”才能得以培养。

\section{3 以老带新, 培养青年教师的教学课件 的制作能力}

虽然现在的青年教师基本不需要自己 制作教学课件, 但教学课件的制作能力还是 很重要的, 只有自己体会到怎么制作教学课 件, 知道了制作和使用教学课件时常见的问 题, 才有可能正确有效地使用教学课件, 也
才有可能对现有教学课件进行修改和完善, 在教学需要的时候制作出自己的教学课件, 为了尽快提高青年教师的教学能力, 青年教 师可以在老教师的指导下快速地掌握教学 课件的制作方法, 避免教学课件制作过程中 常见的一些错误, 只有在熟悉教学课件的设 计过程和内容方法的前提下, 才有可能在课 堂上充分表现 “作为教师的表达能力”。

\subsection{1 信息量过大}

信息量过大, 实则是无效信息, 不但不 能提高教学质量, 反而会严重降低教学质 量。教学信息量要符合学生的认知规律, 比 板书时的信息量多20 30\%较为合适。

\subsection{2 教学内容整页呈现}

教学内容整页呈现, 学生容易产生较大 的压力感和抵触情绪, 同时教师的教学也会 变成 “读屏幕” ，教师会变成 “放映员” 和 “解说员”, 不利于师生之间的交流与沟通。 教学内容的呈现速度应与教师的讲解速度 相配合, 更要考虑到学生的认知能力和接受 能力, 应逐字逐句逐行逐段把握在合适的节 奏下阶段性呈现。特别地, 正如图1所示, 教学课件的内涵大都是不在屏幕上呈现的, 而是存放在教师的教学笔记和教师的头脑 中的, 是需要教师在课堂教学过程中用语言 表达出来的。

\subsection{3 每页呈现的内容过多}

每页呈现的内容过多, 显得沉重, 学生 的视线容易分散, 不利于集中注意力听讲。 在制作课件时, 每页的内容不宜过多, 最好 是一页只含一个知识点, 或几个有联系的知 识点, 为了减少课件的内容压力, 教学过程 中解释性的内容最好不出现在教学课件的 字面上（即教学课件的形式中），而是放到 教学课件的内涵中（如图1）。

\subsection{4 文字符号满屏飞}

文字符号满屏飞, 面对满屏的文字符 号, 学生容易疲倦, 产生困意, 影响听课效 果。在制作教学课件时, 要充分利用计算机 软件的图表图形功能, 适当地加入图表图形 不但可以提高学生的理解能力, 还可以提高 学生的学习热情[5]。 


\subsection{5 言表不一}

教师口中说的和随即呈现的内容不一 致, 这种现象对听课的学生来说是一种精神 折磨, 严重影响到课堂教学质量, 这是青年 教师在使用他人制作的教学课件时常见的 问题, 要克服这一点只有花足够的时间和精 力做好备课工作, 避免出现有了教学课件就 不再备课的现象。

\subsection{6 眼不离屏幕}

眼不离屏幕, 是青年教师在教学过程中 十分常见的问题, 这个问题直接影响到教师 与学生在课堂上的眼神交流, 其后果是教师 无法实时观察到学生的反应, 也就讲不上调 整教学节奏以适应学生的学习状态, 从而影 响教学质量。解决的办法就是充分备课, 熟 练掌握教学课件内容, 减少看屏幕的时间, 而把眼神更多地留给学生。

\subsection{7 脚不离讲台}

青年教师在教学过程中容易依赖电脑, 忙于电脑操作, 教师的肢体语言完全丧失, 学生的情绪容易陷入低迷状态, 影响听课效 果。解决的办法是使用移动鼠标, 经常性地 走下讲台, 与学生拉近距离。

\subsection{8 手不离鼠标}

教师在讲课过程中只使用鼠标, 而完全 放弃板书, 这也是青年教师在教学过程中常 见的问题, 为了更好讲解知识, 也为了把学 生的目光转移出屏幕获得休息, 适当的板书 是不可缺少的。解决的办法很简单, 就是在 教学过程中要有适当的板书设计。

以上这些常见问题, 需要在较长的教学 实践过程中不断摸索才能够真正克服, 但有 了老教师的指导, 青年教师可以在较短的时 间内克服, 以更快的速度提高教学能力。

\section{4 以老跟新, 在教学过程中实施对青年 教师教学的纠偏纠错过程}

在经过一个完整的 “以老带新” 教学过 程后, 青年教师第一次独立走上讲台时, 还 要加入一个 “以老跟新” 的过程, 实施办法 就是老教师定向和随机地听青年教师上课, 从中发现问题, 与青年教师交流, 实施对青 年教师教学过程的纠偏纠错。经过 “以老跟
新” 的过程后, 青年教师的教学能力可以得 到进一步提升。

\section{3. 结束语}

高校青年教师教学能力的培养直接影 响高校的教学质量, 培养 “作为教师的表达 能力” 是培养高校青年教师教学能力所面临 的最紧迫的任务, 我们以教学课件为抓手, 实施 “以老带新” 和 “以新跟老” 两个环节 对青年教师的教学能力进行培养, 以期青年 教师能够较快成长为一名合格的高校教师。

\section{致谢}

本文为北京印刷学院重点教改项目《提 高青年教师教学能力的方法研究》 (22150114021)的阶段性成果之一。

\section{References}

[1] $\mathrm{Xu}$ cuixia and Fan xiaodong, The thinking of strengthening the teaching ability of young teachers in colleges and universities, Human Resource Management, vol.12(2010), pp. 125-126, 2010.

[2] Gao jing, Strengthen the research of the teaching ability of young teachers in colleges and universities, Shaanxi Jiaoyu,vol.3(2012), pp. 52-53, 2012.

[3] Li junkao and Li yan, Research of the basic effective teaching theory in classroom management, Education Exploration, vol.2(2009), pp. 54-55, 2009.

[4] Cao xiao and Yao liming and Huang shuzhen, Discussing the countermeasures of teaching effectiveness in the university classroom, Higher Education Exploration, vol. 2(2012), pp. 70-75, 2012.

[5] Chen yue, Creating teaching courseware to improve the teaching effect, Journal of Nanjing Institute of Technology(Social Science Edition), vol. 1(2003), pp. 39-42, 2003. 